\title{
The Research and Design of the Materials Inventory Management System based on the digital pipeline
}

\author{
Zhongli $\mathrm{YU}^{1, \mathrm{a}}$, Xiaodong WANG ${ }^{2, \mathrm{~b}}$, Yun $\mathrm{LIAO}^{3, \mathrm{c}}$, Xingxing YAO ${ }^{1, d}$ \\ ${ }^{1}$ Faculty of Information Engineering and Automation, Kunming University of Science and \\ Technology, Kunming Yunnan, 650500, China \\ 2 Engineering Research Center for Mineral Pipeline Transportation of Yunnan Province, Kunming \\ Yunnan, 650500, China \\ ${ }^{3}$ School of software, Yunnan University, Kunming 650091, China \\ aemail: 293303305@qq.com, bemail: 1377403525@qq.com, 'email: 676295641@qq.com, demail: \\ 670783132@qq.com
}

\section{Keywords: Inventory Management; Monitoring; Material; System; B/S Structure}

\begin{abstract}
This paper based on the present development situation of the most enterprises material inventory management system. Aiming at the existed problems and deficiency of the materials inventory management system, combined with the actual needs of modern inventory management and advanced technology of computer software development technology, and designed a scientific and practical materials inventory management process. The process can monitor the order information of the materials, and provide some functions the real-time querying, report printing and the annual inventory analysis, etc, achieved a materials inventory management system based on $\mathrm{B} / \mathrm{S}$ structure. The practical application shows that the system has good practicability and maneuverability.
\end{abstract}

\section{Introduction}

Inventory is very important for an enterprise. On the one hand, a large number of inventories must be purchased by a lot of liquidity, which may cause the company's liquidity shortage; on the other hand, the inventories can be treated as a backup supplies to ease the contradiction between supply and demand when supply tension or supply shortage. Therefore, the company needs to grasp the critical point of inventory to avoid the large backlog inventory and the emergency of needing large amount of materials. This is a very worthy of study. In general, the Inventory not only to meet the demand of normal production, but also to control inventory, to ensure the normal operation of the company and avoid to take up company a lot of liquidity, which has become the important factors which restrict the development of the enterprise, and high importance should be attached to them[1]. However, there exists a variety of negative factors in actual business operations: the complexity of the production process, the number of warehouses is too much and geographically dispersed, the frequent changes of the supplier, the demand changes of off-season and busy season, due to these factors, it is too difficult to make accurate inventory arrangement for the enterprises and affect the further development of the enterprises [2].

In order to realize the normal operation of the company, not only to achieve the management of inventory, but also need to make inventory management convenient and practical. Receiving shipments on time and checking out order information real-time and accurately, the realization of these functions is not only related to the computer software technology, but also related to the level of spare parts management now, only the management method of spare parts is scientific and practical, it will be convenient to use after the function realization[3]. Through years of practice, each company has a set of management methods suitable for its company, and through combing with the inventory management methods and advanced computer technology, it is better to manage the inventory.

Due to the mature and development of the information management technology, and the management methods become more and more scientific, which caused the computer technology, 
network communication technology and other related technology developed rapidly, information system became more and more perfect[4]. But there still exists some shortcomings for complex materials inventory management system. Aiming at this problem, we propose the materials inventory management system based on digital pipeline, by analyzing the important process of inventory and optimizing the process, and then take the management of the department and authority of the role, which will make it better to achieve the management of materials inventory.

\section{Key Technology of the System}

Report Designer of Stimulsoft Reports.Net :Because there are a large amount of materials in the inventory, the operator often miss goods when dealing with the materials inventory, it is inconvenient for company leaders when they check the materials inventory, the financial sector operator wishes to view the data in the mainstream office software, based on the above reasons, the system introduces Report Designer of Stimulsoft Reports.Net. By using this reporting software, users can edit the reports over the Web directly, which can obtain data from MS SQL、Oracle、 ODBC and others databases directly, Users can export the report to Adobe PDF, Microsoft Office and other software, the export format can be PDF, Excel, Word and other formats, etc. By reporting technology, aggregates and organizes data to facilitate leadership to observe [5].

The technology of Silverlight: Microsoft Silverlight is a plug-ins of cross-browser and cross-platform based on Microsoft .NET Framework. It can run on the platform of Mac or Windows, and has some function of Flash, and can display pictures, animation or video on most major browsers. In the process of the materials inventory management, by using the reporting software, it can bring some help to the operator, and the use of Silverlight technology is to create and render the designed reports [6]. And by dealing with the background data, it can generate line charts, pie charts and other graphics, provides the brilliant and intuitive interface to the user.

\section{System Design Scheme}

By analyzing the relevant standards and workflows of each company's materials inventory management, combined with the actual work environment, and divided the materials inventory management into five parts, then materials order information can be reflected by observing the flow of five materials inventories, the specific process is as follows:

Maintenance of plan inventory: each department needs to report materials purchase plan monthly, and related leaders audit it, all the materials need to be purchased would be in the plan inventory after reviewed.

Maintenance of inventory in transit: the operator of inventory in transit makes contract with merchants according to the purchasing plan, and fills the corresponding contract number in materials inventory management system.

Maintenance of company inventory: All the purchased materials should be put in the inventory of company, the operator of inventory of company places the materials according to the standard, and then allocates the materials to each department according to the plan of purchasing department.

Maintenance of department inventory: the materials allocated from company should be put in the inventory of department, the operator of inventory of department places the materials according to the standard.

Maintenance of equipment inventory: there exists equipment failure in the process of production, the department heads need to report the equipment maintenance plan, Equipment maintenance program is a separate process, leaders at all levels need to review.

As shown in Figure1 is the function structure of materials inventory management system. 


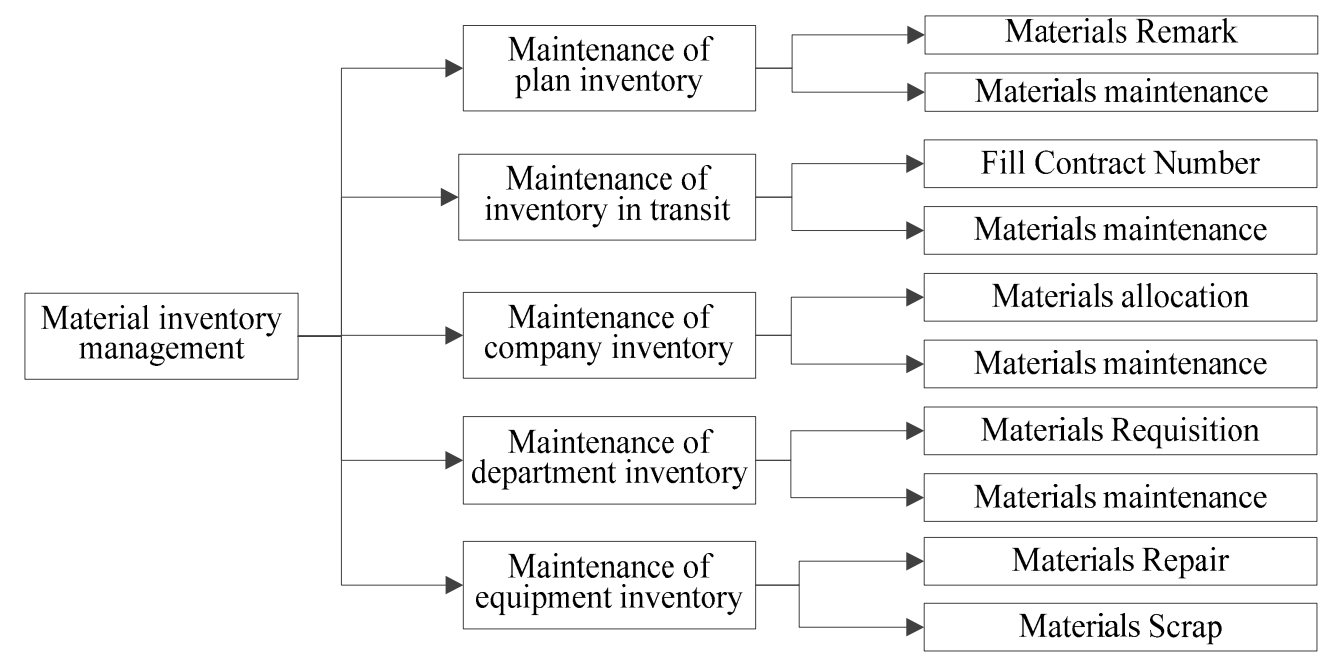

Fig.1. The function structure of materials inventory management system

\section{System Workflow Analyses}

Maintenance of plan inventory: Maintenance of plan inventory involves the applicant of materials plan, department leaders in charge of, department competent leadership and operator of materials department. Due to the review process is very complex, therefore, it is too necessary to observe the process regularly, and know which step the process goes, dealing with the exception timely when there is an exception. The specified review process of plan inventory is as follows: Departments at all levels declare materials plan, and then report the plan to the materials department leaders in charge, the materials department leaders in charge audit the plan, if the materials department leaders in charge do not approve the plan, then the materials department leaders in charge give feedback suggestions, if the materials department leaders in charge approve the plan, the plan would be reported to the materials department competent leadership to audit; the materials department competent leadership audit the plan approved by the materials department leaders in charge, if the materials department competent leadership do not approve the plan, then the materials department competent leadership give feedback suggestions, if the materials department competent leadership approve the plan, then the materials department competent leadership make remarks about the plan, the remarks contain some information about the materials. Then the operator makes notation for the materials can not to buy, when the applicant does not receive some materials, the applicant can knows the reason by viewing notes. As shown in Figure 2 is the review process of plan inventory.

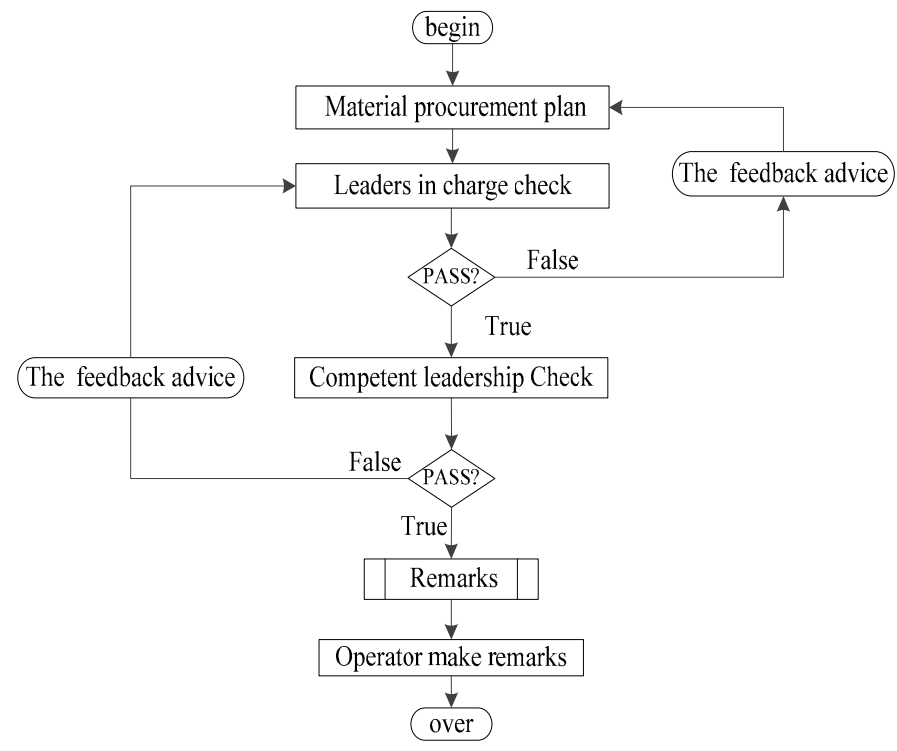

Fig.2. The review process of plan inventory 
Maintenance of inventory in transit: Maintenance of inventory in transit involves the operator of inventory in transit, the leadership of inventory in transit and suppliers, the steps of the process is very simple, but a lot of information needs to be attention, it is important to know the inventory information by observing certain fields and message information of the system. The specified review process of plan inventory is as follows: After the end of the review process of plan inventory, operator of inventory in transit starts to purchase materials. Procurement process procedures are as follows: First, the operator of inventory in transit classifies and gathers the materials which declared from all departments, the operator of inventory in transit should use the reporting software to improve the efficiency as much as possible in the process of gathering materials; and then the leadership of inventory in transit signs the contracts with different suppliers according to the materials suppliers can provide. When there are many suppliers can provide some materials, the leadership of inventory in transit should considerate the reputation, business industry of the suppliers and the lowest price the suppliers can provide. If the contract number exists and no materials need to be received, then it showed that the contracts have been signed, but the materials have not reached the company's inventory; if the contract number does not exist and no materials need to be received, then it showed that the materials have reached the company's inventory, and the materials haven't been allocated, then the leadership of in transit should arrange the operator of inventory in transit to allocate the materials as soon as possible; if there are materials need to be received, then it showed that the materials have reached the company inventory, the applicant needs to be ready to receive materials as soon as possible.

Knowing the materials' order information is very important, in the actual production process, sometimes, some certain materials are needed urgently, but there are no materials in the inventory at this time, by observing the status information of the order, know the information of the order timely and get the materials the first time, minimize losses caused by these emergencies. Because there are too many uncertain factors can affect the materials' arrive during the transportation, therefore, in some special cases, the leadership of inventory should make a telephone with the suppliers to ensure the materials' arrived timely

Maintenance of company inventory: Maintenance of company inventory involves the operator of company inventory and the department materials plan applicant, the company inventory is divided into two categories: the company's existing inventory and the procuring materials in accordance with the subscription plan monthly. The work of the operator of company inventory is divided into three parts: arrange the received materials, send materials to the various departments and organize inventory. The work of the department materials plan applicant is to arrange the materials plan of the department.

The maintenance of company inventory is to achieve the ultimate goal of zero inventories. There accumulates a lot of inventories before using the system, these inventories not only take the company's place, but also lose value for accumulating too long. Therefore, when the materials plan applicant plans to declare materials, check the company's inventory in the system firstly, if the company's inventory has the materials, the department materials plan applicant can apply the materials to the operator of company inventory; if the company's inventory has not the materials, the department materials plan applicant should declare materials according to the process monthly.

Maintenance of department inventory: Maintenance of department inventory involves the operator of company inventory, the operator of department inventory and the leadership of the department. Department inventory consists of two parts: maintenance of the materials sent from the company's inventory and materials from the department's inventory, maintenance of the materials sent from the company's inventory means: when the company inventory operator sends a request, the department inventory operator checks the materials received from company's inventory, the department inventory operator checks the type and quantity of goods received to see whether it is the same with the plan reported, if it is not the same with the plan, the information should be feedback to the company inventory staff, if it is the same with the plan, operator of department inventory reported the information organized carefully to the department leadership, the leadership views the information, and then arrange the department of materials inventory operator to organize 
these materials. Maintenance of the company's inventory means: The department personnel register personnel who requisites materials, sorting out the materials of need urgently and backlog materials.

The ultimate goal of the maintenance of department inventory is to achieve zero inventories. But this ideal situation does not exist in the actual production process, because there always some spare materials in department inventory, it is necessary to classify the materials according to the rules in order to facilitate requisitioned materials. As shown in Figure 3 is the process of receiving materials of department inventory.

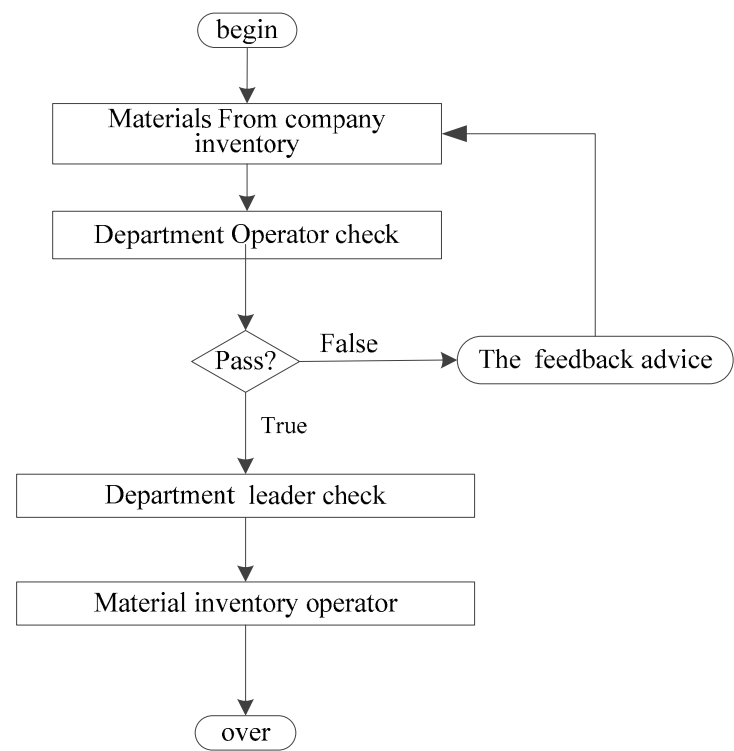

Fig.3. The process of receiving materials of department inventory

Maintenance of equipment inventory: Maintenance of equipment inventory involves the operator of equipment inventory, the sector leaders and equipment inventory auditor. management and maintenance of materials can be achieved by the first four inventories, but some expensive equipment may have equipment failure in the production and management of companies, the operator of equipment inventory needs to apply for maintain plan to the sector leaders when the equipment failure occurs, the sector leaders will audit the plan, if the sector leaders approves the plan, the plan will be send to the equipment inventory department, otherwise, the sector leaders should give feedback recommendations to the operator of equipment inventory; and these equipment need to send to the equipment inventory, reviewers will judge the damage of the equipment, if it cannot repair, then adopt scrap processing; if it can repair, maintenance cost will be the further consideration, and if the repair cost is too large, it is recommended that direct scrapped; if the maintenance costs can be afforded, then sending it back to the original unit after repair. In fact, there are two ways of maintenance of equipment: the first way is the company's own equipment maintenance department maintain the equipment, but sometimes, company don't have enough ability to repair themselves, so the second way is the company let other companies to repair, there are anther two reason to scrap equipment: First, sometimes, national or government will redefine some security indicators of production facilities, for the equipment which does not meet the relevant standards, it has to be scraped. Secondly, the equipment has exceeded the safety shelf life; although it can run normally, but it has to be scraped too. As shown in Figure 4 is the review process of equipment maintenance. 


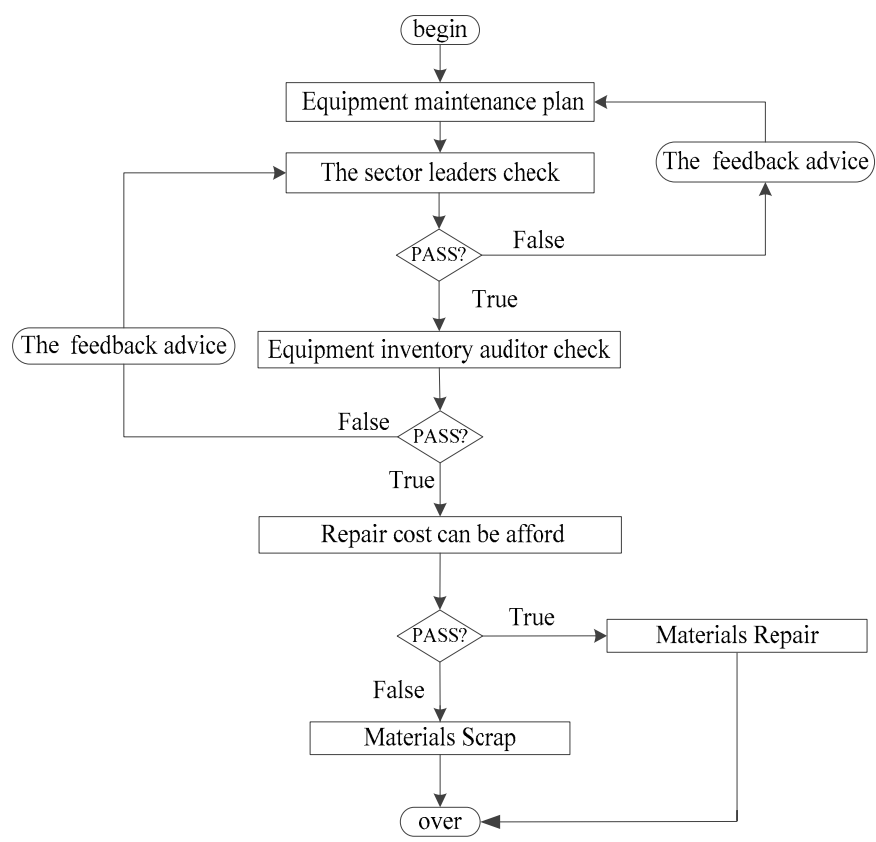

Fig.4. The review process of equipment maintenance

\section{Conclusion}

This paper designs, develops and implements a materials inventory management system based on digital pipeline. This system takes Visual Studio 2012 as development tools, SQL 2008 as the backend database, $\mathrm{C} \#$ as the programming language, adopts $\mathrm{B} / \mathrm{S}$ architecture and Microsoft Silverlight technology, Not only can realize the function of the inventory management, but also can present particular data the leadership focus on intuitively. Currently, a large domestic pipeline company has using this system to maintain their inventory, through half a year's operation shows that: the development and application of materials inventory management system can improve the efficiency and reduce the workload of materials inventory management personnel.

\section{Acknowledgement}

Xiaodong Wang is the corresponding author. This work is supported by Science \& Research Prog ram of Yunnan province (2012CA022\& 2013DH034).

\section{References}

[1] Xie Fang, Liu Xiao-yu, Wang Hai-yan. Design and Accomplishment of Inventory Management System Based on CIMS[J]. Coal Mine Machinery, 2011:32 (05):259-261.

[2] Tang Ya-ling, QIin Feng, Cui Zhi-ming. Research on Design Pattern of Inventory Management Based on.NET Platform[J]. Computer Technology and Development, 2006:16 (12):133-135,138

[3] Huang Zhao-niu. The Application Analysis of Management Information System in Service Parts Inventory Management[J]. Logistics Engineering and Management, 2011:33 (07):44-46.

[4] Zhou Di-ming. The Research and Development of inventory management information system[J]. Journal of Hunan University of Science and Engineering, 2006:27 (11):232-235.

[5] Jing Wei, Zhou Guo-xiang. Research and implementation of small and medium enterprise oriented intelligent report system[J]. Journal of Hefei University of Technology (Natural Science), 2012:35 (7):904-907.

[6] Li Guang, Wang Jian-lin, Zhao Li-qiang, YU Tao. Design of flexible production report system based on Silverlight[J]. Computer Engineering and Design, 2013:34 (7):2595-2598, 2608. 